Chronic Obstructive Pulmonary Diseases:

Journal of the COPD Foundation

Original Research

\title{
Effects of a Highly Portable Noninvasive Open Ventilation System on Activities of Daily Living in Patients with COPD
}

Brian W. Carlin, MD, FCCP, ${ }^{1}$ Kimberly S. Wiles, BS, RRT, ${ }^{2}$ Robert W. McCoy, BS, RRT, FAARC, ${ }^{3}$

Toni Brennan, RRT, ${ }^{2}$ Dan Easley, BS, ${ }^{2}$ Richard J. Morishige, MS, RRT ${ }^{4}$

\section{Abstract}

Background: For patients with chronic obstructive pulmonary disease (COPD), an increase in exercise tolerance and ability to perform activities of daily living (ADLs) can mean an improved quality of life with fewer exacerbations and lower health care expenses. We evaluated a wearable, noninvasive open ventilation (NIOV) system designed to enhance exercise capacity and increase mobility.

Methods: Patients with stable, oxygen-dependent COPD were recruited for this prospective, open-label, crossover study. Inclusion criteria included supplemental oxygen use, elevated dyspnea score, and the ability to perform ADLs. Patients performed a selected ADL for as long as tolerable while using standard oxygen therapy. Following a rest period, the same ADL was repeated using the NIOV system. ADL endurance time, oxyhemoglobin saturation measured by pulse oximeter $\left(\mathrm{SpO}_{2}\right)$, dyspnea, fatigue, and discomfort scores were recorded.

Results: Thirty patients were enrolled and 29 patients completed the study. Mean ADL endurance increased by $85 \%$ (13.4 vs. $7.2 \mathrm{~min}$ ) using NIOV compared with oxygen therapy ( $\mathrm{p}<0.0001)$. Mean $\mathrm{SpO}_{2}$ was significantly higher during ADLs using NIOV versus oxygen therapy ( $p<0.0001)$. Median dyspnea, fatigue, and discomfort scores were significantly lower using NIOV during ADLs compared to oxygen therapy $(\mathrm{p}<0.01)$. No device-related adverse events were observed.

Conclusions: This study demonstrated that a novel, portable noninvasive open ventilation system can improve ADL performance in the home setting. Compared to standard oxygen therapy, the NIOV system provided statistically and clinically significant increases in ADL endurance time and oxygenation, while decreasing dyspnea, fatigue, and discomfort. The NIOV system appears to offer a practical option for increasing activity and exercise tolerance in oxygen-dependent patients with COPD.

\footnotetext{
Abbreviations: 6-minute walk distance, 6MWD; activity of daily living. ADL; noninvasive open ventilation, NIOV; noninvasive ventilation, NIV; oxyhemoglobin saturation measured by pulse oximeter, $\mathrm{SpO}_{2}$; modified Medical Research Council, mMRC

Funding Support: This study was sponsored by Breathe Technologies, Inc; Irvine, California.

Date of Acceptance: October 1, 2014

Citation: Carlin BM, Wiles KS, McCoy RW, Brennan T, Easley D, Morishige RJ. Effects of a highly portable noninvasive open ventilation system on activities of daily living in patients with COPD. J COPD F. 2015;2(1): 35-47. doi: http://dx.doi.org/10.15326.
}

\section{Drexel University School of Medicine, Pittsburgh, Pennsylvania}

\section{Klingensmith HealthCare, Ford City, Pennsylvania}

3 Valley Inspired Products, Apple Valley, Minnesota

4 Clinical Research Consulting, Castro Valley, California

\section{Address correspondence to:}

Brian W. Carlin, MD, FCCP

Assistant Professor of Medicine

Drexel University School of Medicine

Sleep Medicine and Lung Health Consultants

Pittsburgh, Pennsylvania

Email: bwcmd@yahoo.com

Phone: (412)298-8944 
Keywords:

Activity of daily living; COPD; dyspnea; noninvasive ventilation; pulmonary rehabilitation

This research was originally presented as a poster presentation at the American College of Chest Physicians Conference, October 2012 in Atlanta, Georgia.

\section{Introduction}

Disease limited exercise capacity, and its impact on the ability to perform activities of daily living (ADLs), is a common and debilitating problem for patients with chronic obstructive pulmonary disease (COPD). Clinical data show that patients with COPD are generally less active compared with healthy age-matched peers, ${ }^{1}$ and that lower activity is associated with adverse clinical outcomes, including increased exacerbations, hospital admissions, and mortality. ${ }^{2-4}$ Thus, therapies or methods that can effectively increase daily activity levels and reduce the incidence of hospital admissions and exacerbations are a focal point of COPD disease management, as they may yield substantial economic and social benefits. ${ }^{3}$

Pulmonary rehabilitation is a well-established example, having been shown to improve exercise capacity, dyspnea, and health-related quality of life. ${ }^{5-8}$ In particular, enhanced physical capacity plays a key role in the overall effectiveness of pulmonary rehabilitation, and data suggest that increased exercise intensity and endurance results in increased physiologic benefits. ${ }^{9,10}$ The difficulty, of course, is that accomplishing even modest activities, let alone performing vigorous and/ or prolonged exercise, is challenging for many patients with advanced COPD. Several adjunctive therapies have been explored to enhance exercise training and pulmonary rehabilitation, reduce symptoms, and facilitate activities of daily life. These include the use of supplemental oxygen, ${ }^{11,12}$ heliox, ${ }^{13,14}$ neuromuscular stimulation, ${ }^{15}$ inspiratory muscle training, ${ }^{16}$ bronchodilators, ${ }^{17,18}$ anabolic steroids, ${ }^{19,20}$ bronchoscopic lung volume reduction, ${ }^{21,22}$ and noninvasive ventilation. ${ }^{23-28}$

Multiple, interrelated pathophysiologic factors play a role in the exercise intolerance observed in patients with $\mathrm{COPD}^{5}$ including ventilatory impairment, gas exchange limitations, muscle fatigue, and anxiety - all of which can contribute to the overarching symptom of dyspnea. ${ }^{29}$ The degree to which each factor is involved can vary widely between patients as well as between different types of activity. ${ }^{30}$ Thus, treatments aimed at increasing exercise tolerance and minimizing dyspnea often utilize disparate approaches and mechanisms of action to accomplish their goal.

Exercise and ADLs frequently involve ambulation, hence, therapies designed to enhance these activities should be practical for mobile use. In the case of supplemental oxygen, major strides have occurred in the last 2 decades making portable oxygen feasible for everyday use, with numerous devices now available. ${ }^{31-33}$ However, supplemental oxygen alone may be insufficient to address the exertion-related stresses associated with ventilatory insufficiency, ${ }^{34-36}$ and the same progress in device portability has not taken place in the area of noninvasive ventilation (NIV).

In 2007, Dreher and colleagues ${ }^{26}$ demonstrated that NIV used during walking could significantly improve oxygenation, dyspnea, and walking distance in patients with very severe COPD. Since the ventilator used in their study was large and heavy, the authors electively placed the unit on a wheeled cart during walk testing. In a later study performed at the same center, patients with COPD were again walk-tested using NIV. This time, however, patients were asked to carry the ventilator system (weight=7.3 kg) in a backpack during walking, and a markedly different outcome was observed. ${ }^{37}$ Although NIV with supplemental oxygen still improved in-walk oxygenation compared to oxygen therapy alone, dyspnea scores remained unchanged and walk distance worsened by 64 meters. The authors attributed the poor study outcome to the burden imposed on patients of carrying the heavy ventilator system noting that, "more practical and acceptable forms of [ambulatory] ventilatory support" need to be developed.

In the current study, we evaluated the effects of a recently available, wearable, noninvasive ventilator compared to standard oxygen therapy during ADLs in patients with COPD. Based on prior clinical data using this noninvasive ventilator system, ${ }^{38-40}$ we hypothesized that it could improve oxygenation, comfort, dyspnea, and ADL endurance versus standard supplemental oxygen.

\section{Methods}

\section{Patients}

Patients with stable COPD were identified and recruited for this at-home study by accessing the database of 
a durable medical supplies and services company (Klingensmith Healthcare; Ford City, Pennsylvania). Inclusion criteria included current use of supplemental oxygen during rest and exertion, self-reported dyspnearelated activity limitation, and ability to perform ADLs such as walking, cleaning, and climbing stairs. Current tobacco smokers were excluded, as were patients with acute respiratory symptoms, or those with a recent hospitalization. The study received institutional review board (IRB) approval, and patients signed an IRBapproved informed consent form (IRB No. 201102606 , Schulman Associates, Inc; Cincinnati, Ohio). The study was registered on ClinicalTrials.Gov (http:// clinicaltrials.gov; NCT01347931).

\section{Noninvasive Open Ventilation System}

The noninvasive open ventilation system (NIOV) system (Breathe Technologies, Inc; Irvine, California) is Food and Drug Administration-cleared and is designed to provide breath-actuated, tidal volume augmentation and oxygen to adults with respiratory insufficiency. The system consists of a wearable, 1 pound ventilator, and an open, non-sealing, proprietary nasal pillow interface (Figure 1 ). When attached to medical grade, compressed oxygen, the ventilator delivers a preset volume of oxygen ranging from $50-250 \mathrm{~mL}$ during the patient's inspiratory phase. In addition, room air is entrained during volume delivery by way of 2 Venturi ports located on the nasal interface. Depending on the volume setting and factors such as lung compliance and resistance, the total augmentation volume delivered (i.e., oxygen + entrained room air) can exceed $450 \mathrm{~mL}$. $^{41}$ Since the patient's air path retains continuous access to ambient air via the Venturi ports, the ventilator and nasal interface are considered to comprise an open system. Ventilator inspiratory time is set as a function of the total breath cycle time, and is adjustable from $10 \%-40 \%$. Trigger sensitivity is adjustable from 0-9, corresponding to a pressure range of -0.01 to $-0.34 \mathrm{~cm}$ $\mathrm{H}_{2} \mathrm{O}$.

\section{Figure 1. Noninvasive Open Ventilator (NIOV) System}

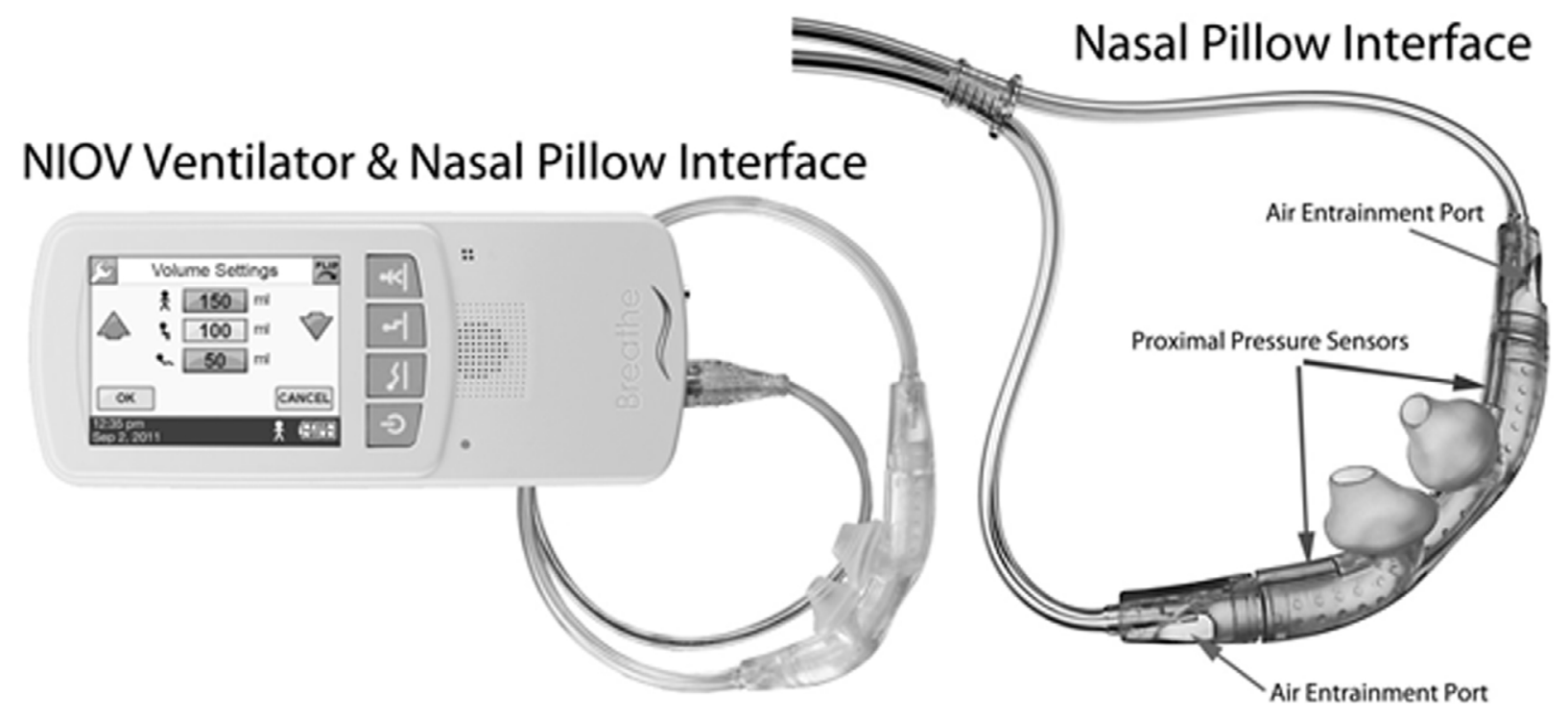

Noninvasive open ventilator (NIOV) system (Breathe Model BT-V2S, Breathe Technologies Inc., Irvine, California) showing the ventilator and nasal pillow interface. The Venturi air entrainment ports are illustrated. Ventilator dimensions are: $3^{1 / 8}$ (h) $\times 1 \frac{1 / 4}{4}$ (d) $\times 7^{1 / 2}(\mathrm{w})$ inches. Weight: $1 \mathrm{lb}$.

\section{Study Protocol}

This was a prospective, non-randomized, openlabel, 2-arm, crossover study, conducted in the home setting. Patients completed a single study day, lasting up to 3 hours. At-home testing and data collection were performed and/or supervised by a registered respiratory therapist. Study measurements included height, weight, blood pressure, heart rate, respiratory 
rate, $\mathrm{ADL}$ endurance time, $\mathrm{SpO}_{2} \quad$ (WristOx $\mathrm{x}_{2}$ Model

\section{Figure 2. Borg, Fatigue, and Discomfort Analog Scales}

3150, Nonin Medical, Inc; Plymouth, Minnesota), Borg dyspnea score, ${ }^{42}$ an 11-point visual analog fatigue score, and an 11-point visual analog discomfort score (Figure 2).

On the day of testing, patients were oriented to the NIOV system, which included a fitting with the NIOV nasal pillow interface and optimizing the ventilator's volume, inspiratory time \%, and trigger sensitivity settings for both rest and activity. For the oxygen treatment arm, patients utilized their

\begin{tabular}{|c|l|}
\hline \multicolumn{2}{|c|}{ Borg Dyspnea Scale } \\
\hline 0 & No breathlessness at all \\
\hline 0.5 & Very Very Slight (just noticeable) \\
\hline 1 & Very Slight \\
\hline 2 & Slight \\
\hline 3 & Moderate \\
\hline 4 & Somewhat Severe \\
\hline 5 & Severe \\
\hline 6 & \\
\hline 7 & Very Severe \\
\hline 8 & \\
\hline 9 & Very Very Severe (Almost Maximum) \\
\hline 10 & Maximum \\
\hline
\end{tabular}
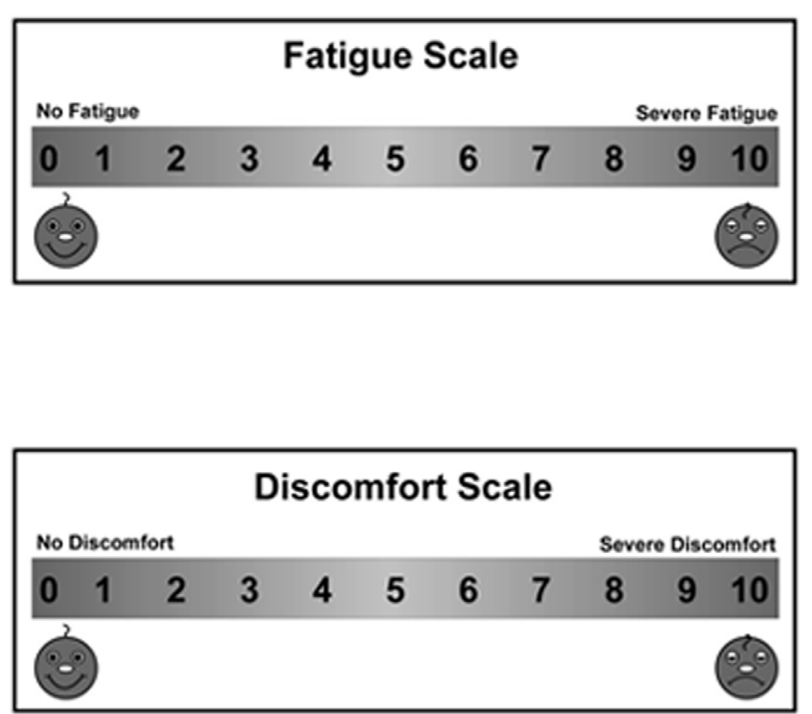

existing nasal cannula at their prescribed flow rates for rest and exertion. Approximately 5 minutes before each test, baseline values were collected for $\mathrm{SpO}_{2}$, heart rate, respiratory rate, dyspnea, fatigue, and discomfort. Patients were asked to perform a self-selected ADL (e.g., walking, stair-climbing, cleaning) for as long as tolerable while using standard oxygen therapy. Following a rest period of at least 15 minutes during which $\mathrm{SpO}_{2}$ and other physiologic parameters were allowed to return to baseline, patients repeated the same ADL, this time using the NIOV system for as long as tolerable. Respiratory rate, heart rate, $\mathrm{ADL}$ endurance time, $\mathrm{SpO}_{2}$, dyspnea, fatigue, and discomfort scores were monitored and recorded for each test.

\section{Outcome Measures and Statistical Analysis}

The primary study outcome measure was ADL endurance time. Secondary endpoints included $\mathrm{SpO}_{2}$, dyspnea, fatigue, and discomfort scores. A per-protocol approach was used for data analyses. Per-protocol was defined as having at least minimal use of both study treatments. A sample size of 26 patient pairs was determined based on the assumption of a true treatment difference in mean ADL endurance time of $4 \pm 7$ minutes using a 2 -tailed, t test ( $\alpha=0.05$, power=0.80). Statistical assessments were performed using ProStat 5.0 (Poly Software International; Pearl River, New
York). Differences between treatment arms for ADL endurance and $\mathrm{SpO}_{2}$ were assessed using a 2-tailed, paired $t$ test. Differences between treatment arms for dyspnea, fatigue, and discomfort scores were compared using a 2-tailed, Wilcoxon matched-pairs, signed-ranks test. Statistical significance was accepted as $\mathrm{p}<0.05$ for all analyses. Data are presented as mean \pm SD unless otherwise noted.

\section{Results}

\section{Patients}

Thirty patients with stable COPD were enrolled between October 2011 and March 2012. Twenty nine patients successfully completed both study treatment arms. One individual (S-11), was unable to use the NIOV system due to nasal congestion and rhinorrhea, and her data were excluded from the efficacy, but not the safety analyses. Descriptive characteristics of the 18 female and 12 male patients are summarized in Table 1 .

\section{ADL Endurance}

Mean ADL endurance time was significantly longer (6.1 minutes, $\mathrm{p}<0.0001$ ) using the NIOV system versus standard oxygen therapy (Figure 3). Of the 29 patients completing both treatments, all but 1 showed greater endurance on the NIOV system versus standard oxygen (Figure 4). 


\section{Table 1. Study Patient Characteristics}

Variable $\quad$ Subjects $(n=30) \quad$ Range

\begin{tabular}{lcc} 
Gender, F/M & $18 / 12$ & \\
\hline Age (years) & $72 \pm 6.3$ & $(57-81)$ \\
\hline Height (inches) & $66 \pm 4.2$ & $(60-76)$ \\
\hline Weight (lbs) & $175 \pm 49.3$ & $(89-300)$ \\
\hline BMI (lbs/in $\left.{ }^{2}\right)$ & $28.2 \pm 7.1$ & $(17.4-44.9)$ \\
\hline $\mathrm{O}_{2}$ Use, Rest (lpm) & 2.6 & $(2-4)$ \\
\hline $\mathrm{O}_{2}$ Use, Exertion (lpm) & 2.8 & $(2-5)$ \\
\hline Median mMRC & 3 & $(1-4)$ \\
\hline
\end{tabular}

Data are mean \pm SD except as specified. MMRC: modified Medical Research Council dyspnea scale

\section{Oxygenation - $\mathrm{SpO}_{2}$}

$\mathrm{SpO}_{2}$ was significantly higher $(4.1 \%, \mathrm{p}<0.0001)$ during ADLs performed using the NIOV system compared with standard oxygen therapy (Figure 5). All 29 patients demonstrated better oxygenation levels while using the NIOV system (Figure 6).

\section{Dyspnea, Fatigue, and Discomfort Scores}

Median dyspnea, fatigue, and discomfort scores were significantly improved when using the NIOV system compared to standard oxygen therapy (Figure 7). For Borg dyspnea scores, 23/29 patients showed less dyspnea using the NIOV system (Figure 8). For fatigue scores, $17 / 29$ patients reported less fatigue while using the NIOV system (Figure 9). For discomfort scores, 19/29 patients reported less discomfort while using the NIOV system (Figure 10).

\section{Figure 3. Activity of Daily Living Endurance Times}

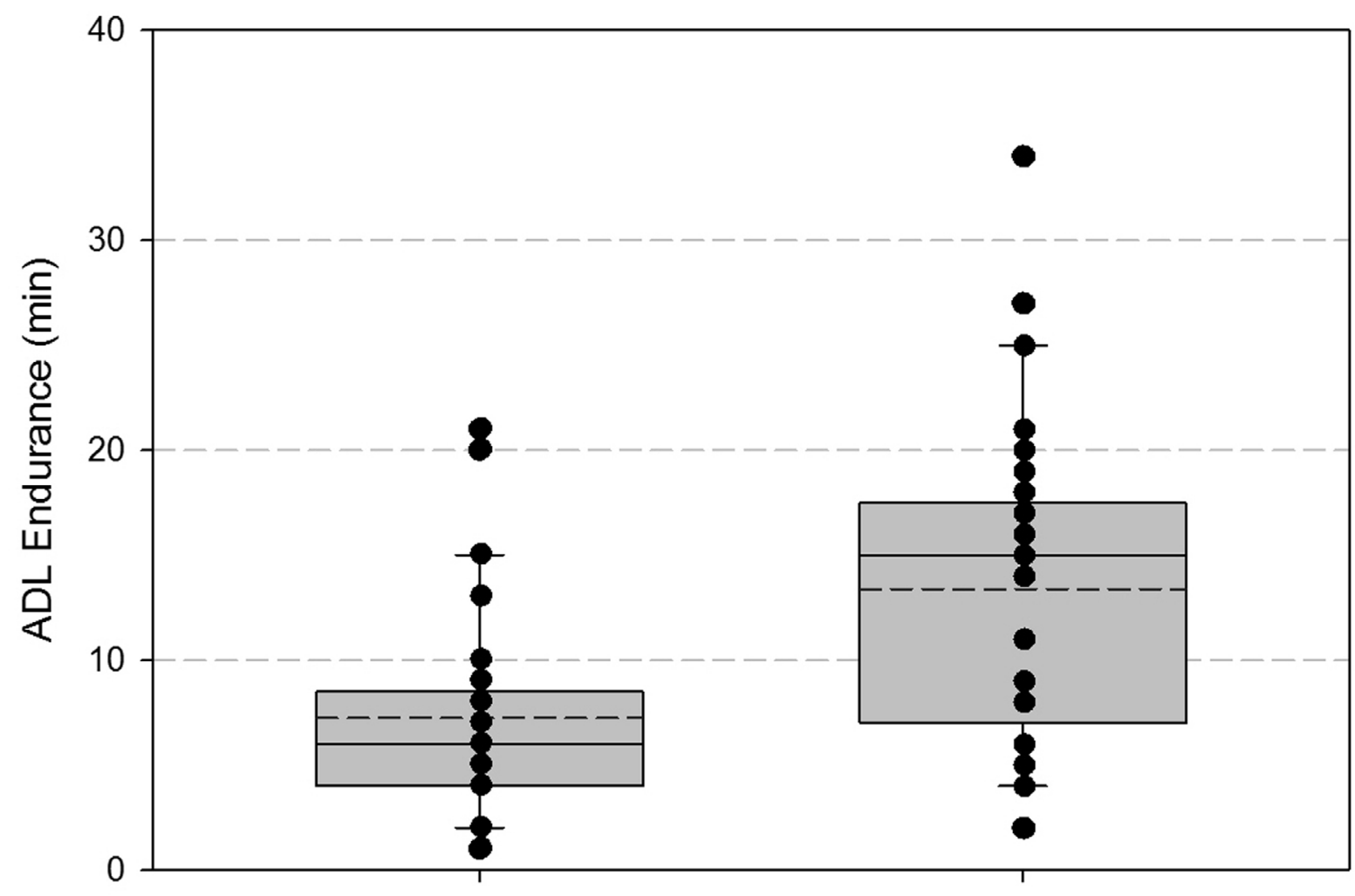

\section{Study Treatments}

ADL endurance times for standard oxygen and noninvasive open ventilation treatment arms. Box plots: 25 and 75 percentile, median (solid line), mean (dashed line) and 95\% confidence intervals (whiskers).

Two-tailed, paired t test $p<0.0001$. 


\section{Figure 4. Differences in Activities of Daily Living Endurance}

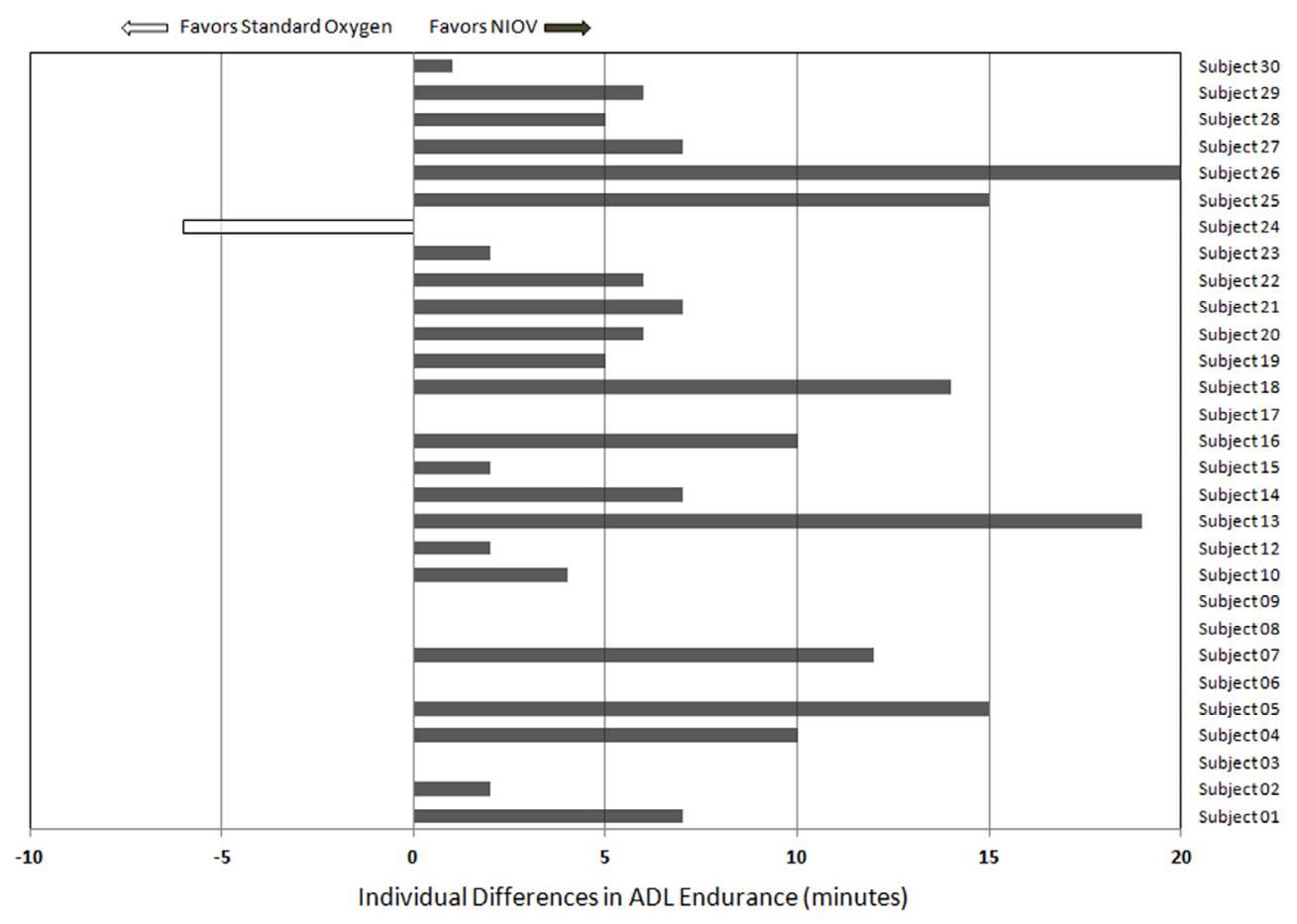

Individual patient differences in ADL endurance for the NIOV system versus standard oxygen.

Figure 5. $\mathrm{SpO}_{2}$ During Standard Oxygen and NIOV Treatment Arms

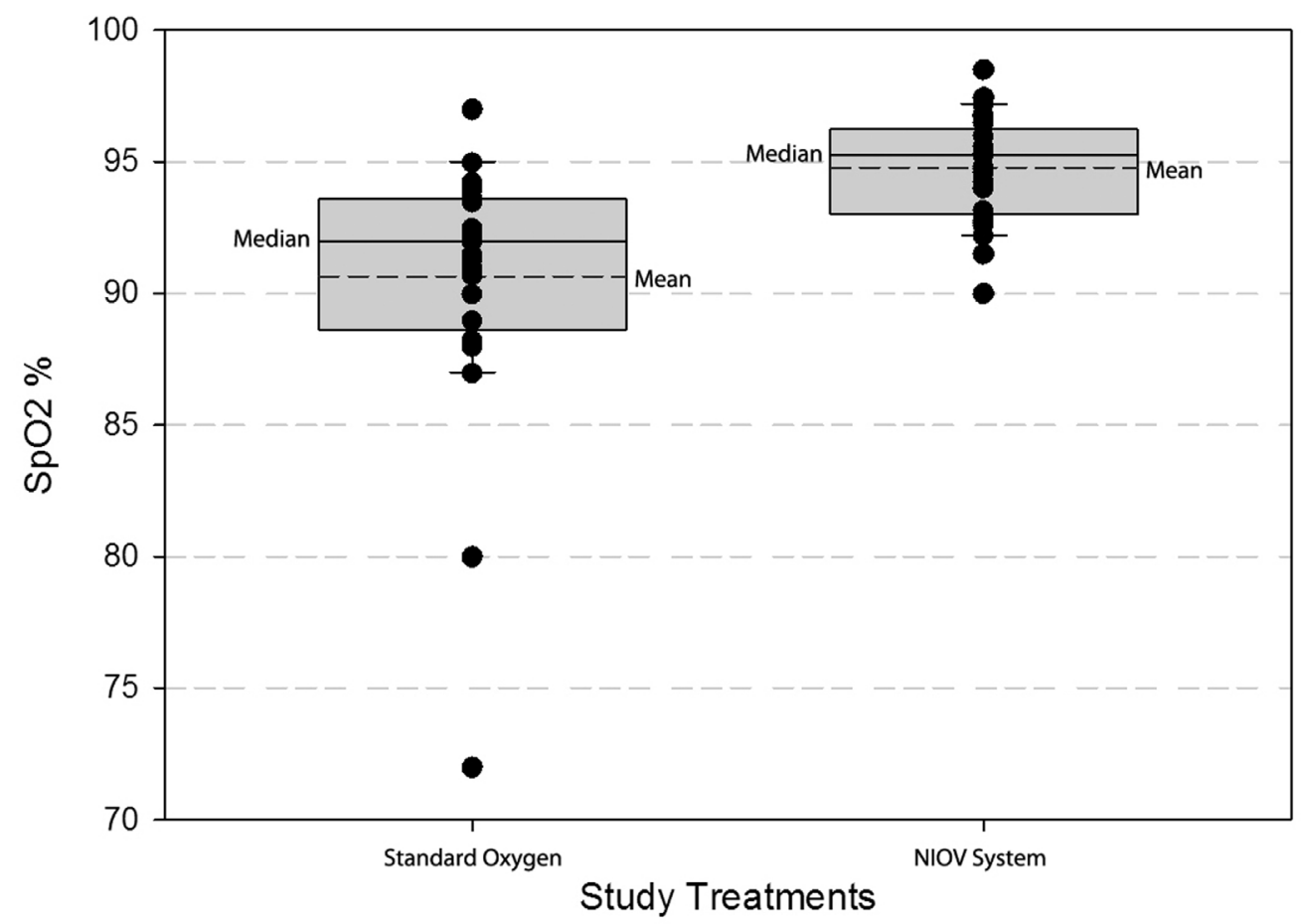

Box plots: 25 and 75 percentile, median (solid line), mean (dashed line) and 95\% confidence intervals (whiskers). Two-tailed paired t test $p<0.0001$.

For personal use only. Permission required for all other uses. 


\section{Figure 6. Differences in $\mathrm{SpO}_{2}$}

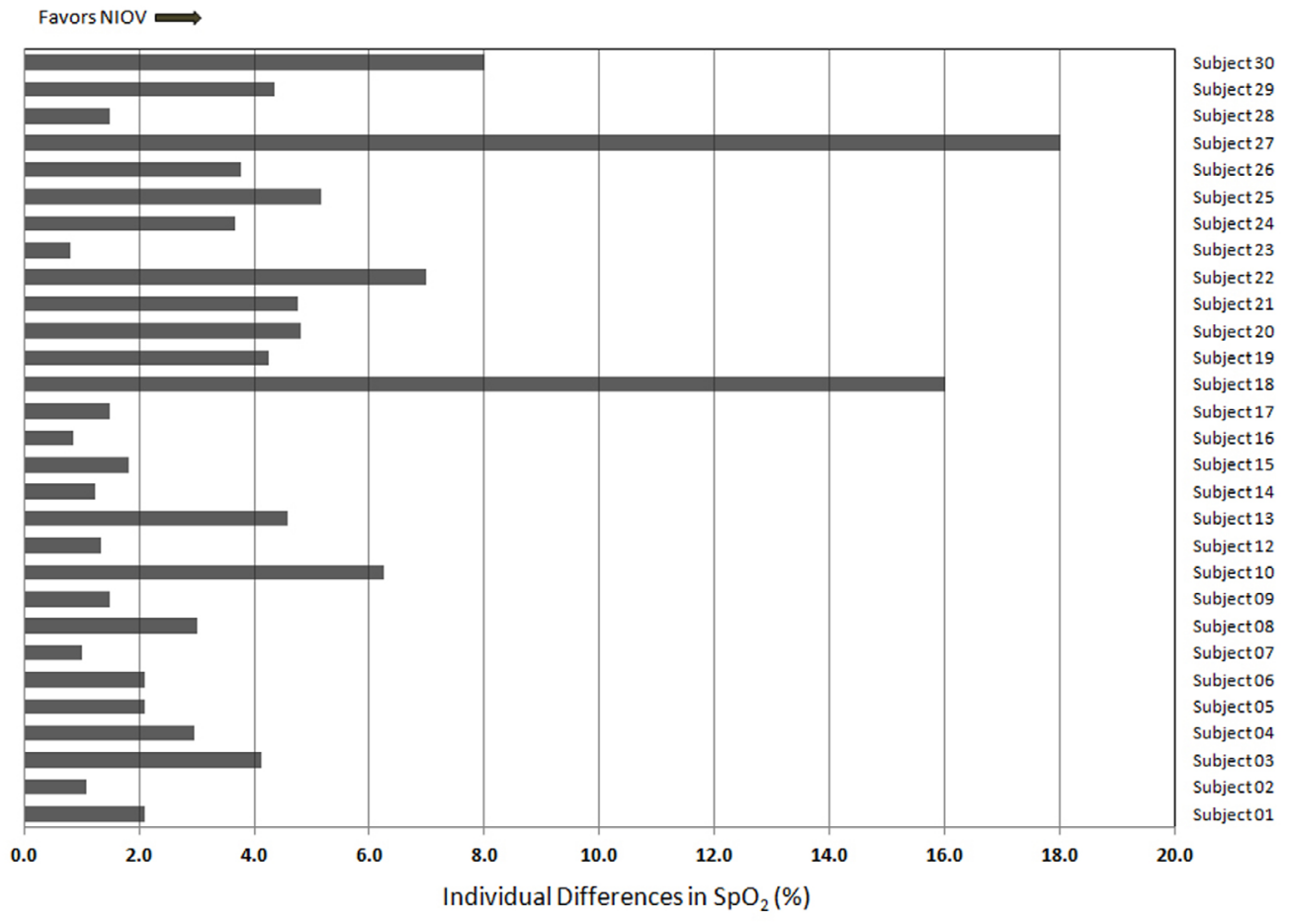

Individual patient differences in $\mathrm{SpO}_{2}$ for the NIOV system versus standard oxygen.

\section{Figure 7. Median Borg Dyspnea, Fatigue, and Discomfort Category Scores}

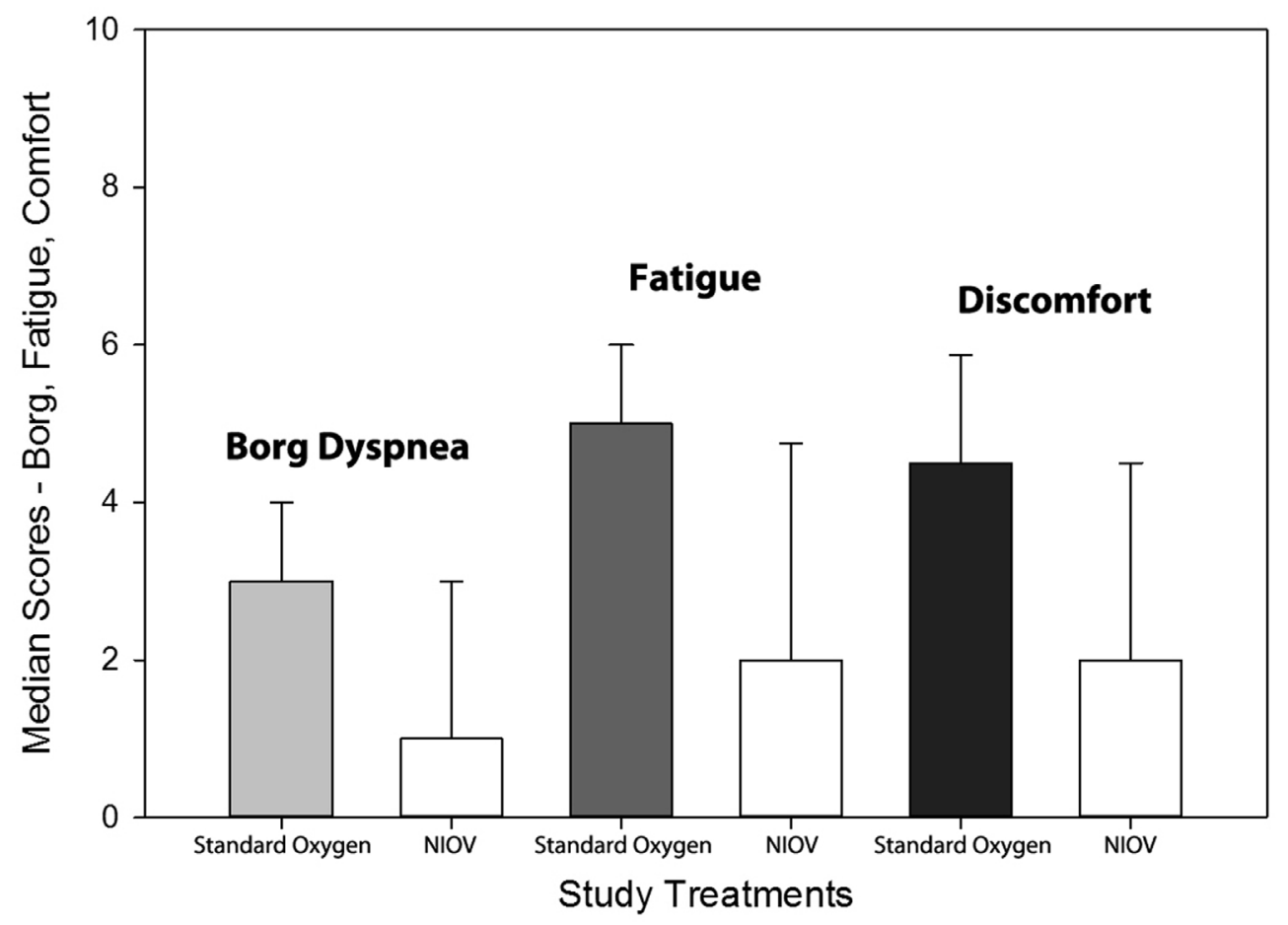

Median Borg dyspnea, fatigue, and discomfort category scores for standard oxygen versus NIOV. Error bars set at $95 \%$ confidence interval. Two-tailed Wilcoxon, matched-pairs signed-ranks tests: Borg, $p<0.0001$; Fatigue, $p=0.0005$; Discomfort, $p=0.0105$. 


\section{Figure 8. Borg Dyspnea Scores}

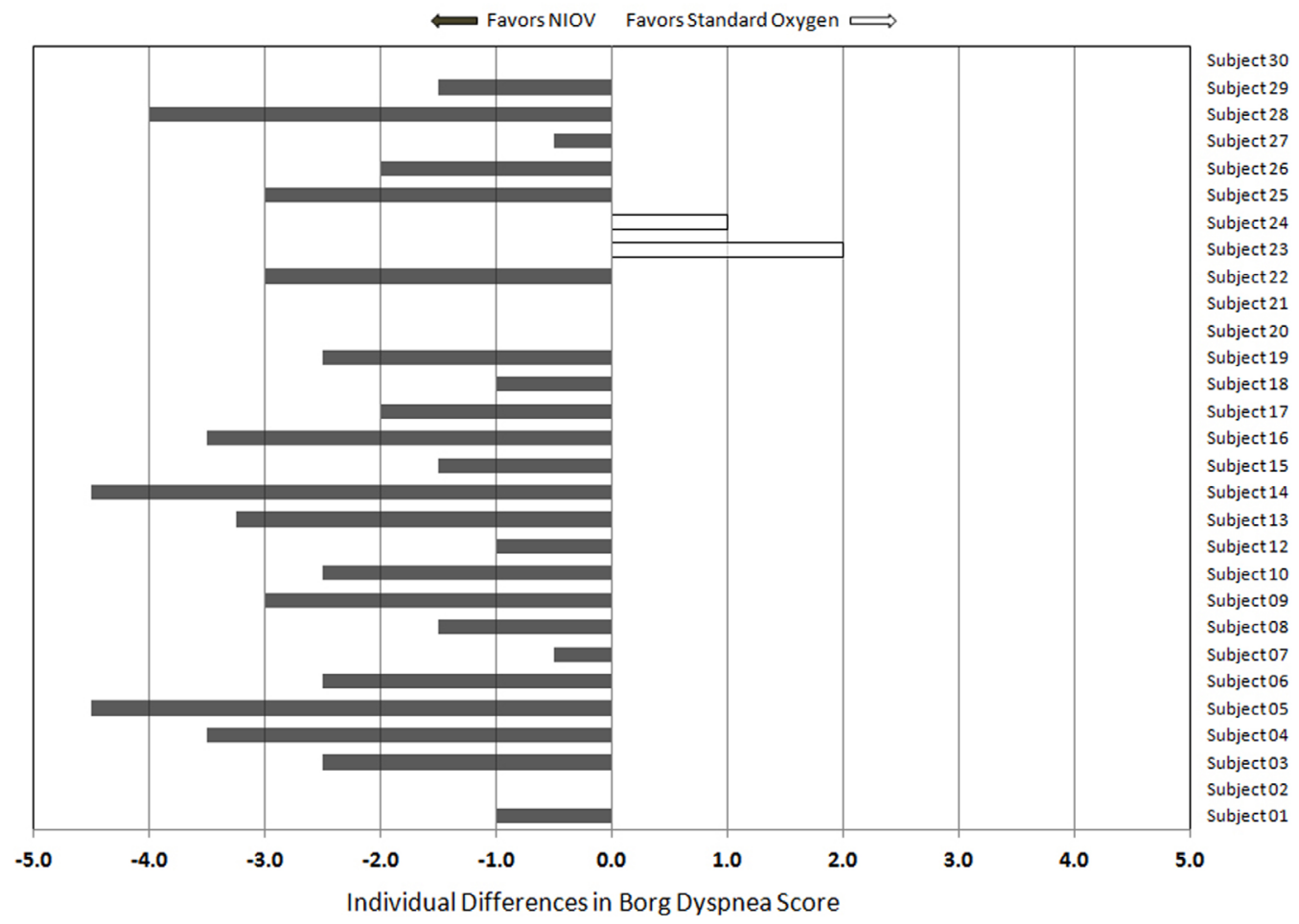

Individual patient differences in Borg dyspnea scores for the NIOV system versus standard oxygen.

Figure 9. Fatigue Scores

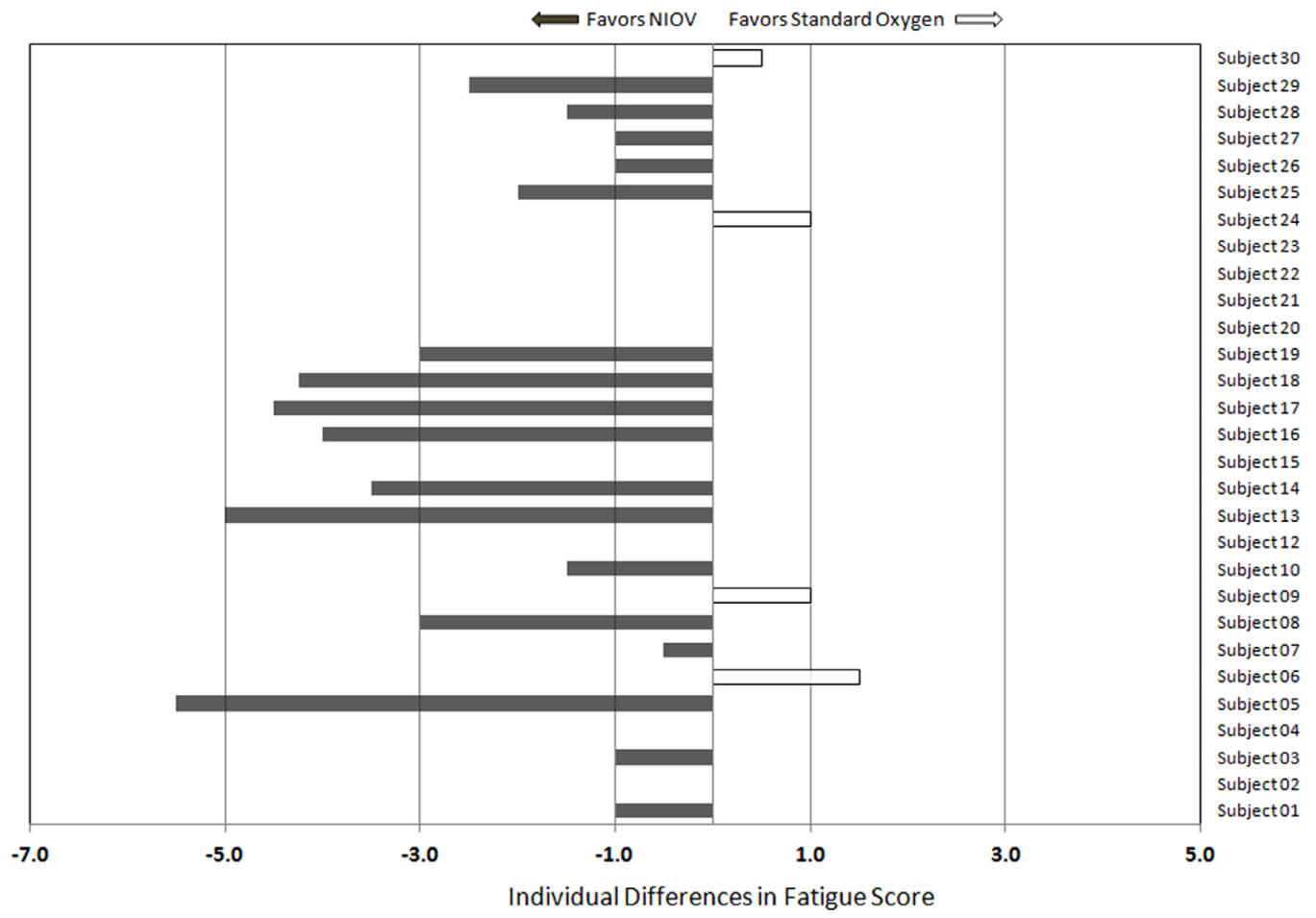

Individual patient differences in fatigue scores for the NIOV system versus standard oxygen.

For personal use only. Permission required for all other uses. 


\section{Figure 10. Discomfort Scores}

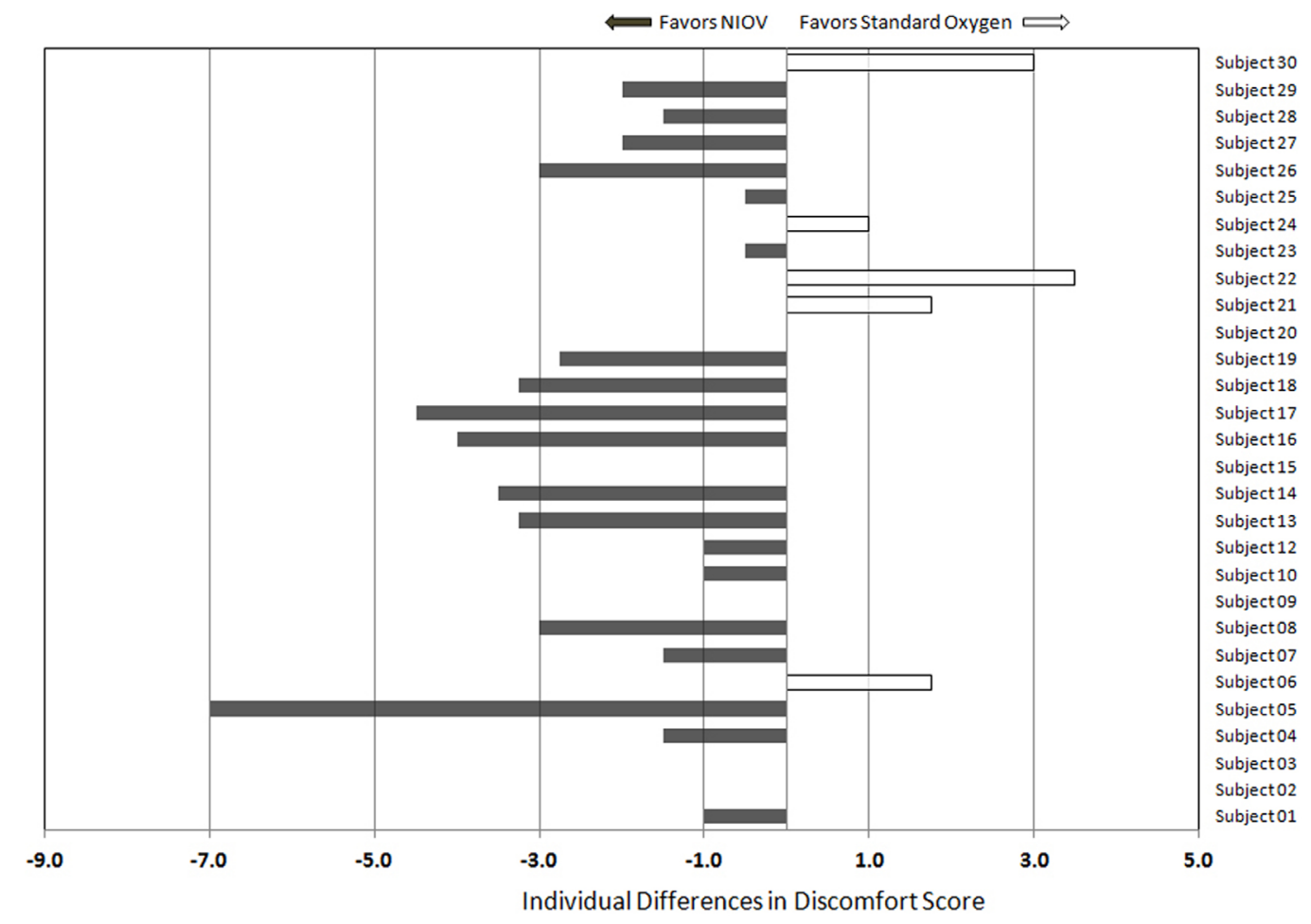

Individual patient differences in discomfort scores for the NIOV system versus. standard oxygen.

\section{Overall Response to NIOV}

An overall summary of the comparisons are described in Table 2. One patient did not show improvement in any of the parameters studied with the use of NIOV therapy. Two patients did not show a response in regards to both fatigue and discomfort. No clinical correlations could be made in these 3 patients regarding lack of response to therapy compared to those patients who did show a response to therapy.

\section{Adverse Events}

A single adverse event was observed during the study (S-11, nasal congestion with rhinorrhea), which did not require treatment, and was deemed unrelated to the study interventions. The NIOV system was well tolerated and received positive comments indicating the device and nasal interface were comfortable to wear.

\section{Table 2 .Activity of Daily Living Performance Using Standard Oxygen Therapy Versus Noninvasive Open Ventilation ( $\mathrm{N}=29$ )}

\section{Variable}

\section{Standard Oxygen NIOV System PValue} Therapy

\begin{tabular}{lccl} 
ADL Endurance (minutes) & $7.24 \pm 5.21$ & $13.38 \pm 7.50$ & $\mathrm{P}<0.0001^{1}$ \\
\hline $\mathrm{SpO} 2 \%$ & $90.65 \pm 4.87$ & $94.78 \pm 1.99$ & $\mathrm{P}<0.0001^{1}$ \\
\hline Borg & 3.00 & 1.00 & $\mathrm{P}<0.0001^{2}$ \\
\hline Borg $(95 \% \mathrm{CI})$ & $2.80-4.07$ & $1.16-2.40$ & \\
\hline Fatigue & 5.00 & 2.00 & $\mathrm{P}=0.0005^{2}$ \\
\hline Fatigue (95\% CI) & $2.56-5.15$ & $2.03-3.77$ & \\
\hline Discomfort & 4.50 & 2.00 & $\mathrm{P}=0.0105^{2}$ \\
\hline Discomfort (95\% CI) & $3.17-4.86$ & $1.96-3.63$ &
\end{tabular}

${ }^{1}$ Mean, 2-tailed paired t test. $\quad{ }^{2}$ Median, 2-tailed Wilcoxon matched-pairs, signed-ranks test. 


\section{Discussion}

In the previously described study by Dreher et al, ${ }^{26}$ with NIV (with the ventilator on a wheeled cart) the improved mean 6MWD increased by 43 meters, the Borg dyspnea score by 2 points and arterial oxygenation by 10.4 torr in patients with very severe COPD. BorghiSilva et $\mathrm{l}^{43}$ compared NIV with standard supplemental oxygen during pulmonary rehabilitation in patients with COPD and reported that NIV increased 6MWD by 75 meters and improved dyspnea and $\mathrm{SpO}_{2}$ versus standard oxygen. van't $\mathrm{Hul}$ and colleagues ${ }^{44}$ showed improvements of $13 \%$ in shuttle walk distance and $76 \%$ in cycle endurance using noninvasive inspiratory pressure support versus sham ventilation in patients with COPD. Using the same NIV system described in the current study, Porszasz et al ${ }^{45}$ reports that compared to standard nasal cannula oxygen, NIOV significantly improved mean exercise tolerance (11.4 minutes vs. 17.6 minutes) and $\mathrm{SpO}_{2}(92.7 \%$ vs. $98.5 \%)$, while decreasing respiratory muscle activation in patients with severe hypoxemic COPD undergoing constant work rate cycle ergometry.

Helium-oxygen mixtures (heliox 80/20), when applied during constant work rate exercise, have been shown to increase exercise tolerance compared with room air by 4.5 minutes (73\%) in patients with moderate-to-severe COPD. ${ }^{13}$ Other studies have reported comparable improvements in exercise endurance and dyspnea. ${ }^{46,47}$ A hyperoxic helium-oxygen mixture (heliox 60/40), used during pulmonary rehabilitation in patients with severe COPD, demonstrated an increased constantload exercise duration of $5.2 \mathrm{~min}$ (120\%), and improved dyspnea and leg discomfort scores. ${ }^{48}$

Emtner et al, using supplemental oxygen during constant work rate exercise in non-hypoxemic patients with severe COPD, showed a 4-minute (38\%) improvement in exercise endurance, but no change in dyspnea compared to room air. ${ }^{11}$ Jolley et al, ${ }^{49}$ evaluating the effects of supplemental oxygen in patients with severe COPD, also reported mixed results. In desaturators (patients showing $\mathrm{SpO}_{2}$ drops of at least $5 \%$ and $<90 \%$ during walking), oxygen increased the mean walk distance by 59 meters (22\%) and improved dyspnea scores by 2 points. For non-desaturators, oxygen therapy only improved dyspnea. In a study of patients with mild-to-severe COPD, Fujimoto et $\mathrm{al}^{50}$ reported that while supplemental oxygen improved $\mathrm{SpO}_{2}$ in all patients, only patients with moderate and severe disease showed increases in 6MWD (24 meters and 32 meters, respectively).

In the current study, the NIOV system increased ADL endurance by $85 \%$ and absolute $\mathrm{SpO}_{2}$ by $4.1 \%$, while significantly decreasing symptoms of dyspnea, fatigue, and discomfort in patients with chronic respiratory insufficiency and exercise intolerance. In a prior clinical trial in patients with oxygen-dependent lung disease (NOVEL-1), ${ }^{40}$ the NIOV system increased the mean 6MWD by 57 meters more than the mean 6MWD of patients using nasal cannula oxygen. A follow-up study of 32 patients with severe, oxygen-dependent COPD (NOVEL-2), ${ }^{39}$ reported that the 6MWD improved by 36 meters while using NIOV compared to using standard oxygen therapy, with a subset of patients (baseline $6 \mathrm{MWD}<300$ meters) improving by 73 meters. In a study to evaluate ease of use, comfort, and preference, 18 patients with severe COPD used the NIOV system for 5 days and found it to be easy to use, comfortable, and indicated a strong preference (median Likert score = 5/5) for using the NIOV system over their standard oxygen systems for performing errands, household tasks, and exercise. ${ }^{38}$ These data, demonstrating improvements in ADL endurance, 6MWD, oxygenation, symptom scores, and preference for use, support the idea that the NIOV system can provide comparable, and in some cases, superior benefits compared to other treatment modalities in patients with advanced chronic lung disease.

Clearly, adjunctive treatments are available that can enhance exercise capacity, improve dyspnea, and potentially increase the benefits of pulmonary rehabilitation. Unfortunately, other than supplemental oxygen therapy, treatment modalities such as standard noninvasive ventilation and heliox have limited applicability for ambulatory use. Conversely, oxygen therapy, while highly portable, is often insufficient to meet the needs of patients with significant ventilatory insufficiency. Thus, mobile devices that address both oxygenation and ventilation needs, and that can be broadly applied to enhance activity levels and increase exercise tolerance, are greatly needed.

Increasing physical activity and exercise endurance in patients with COPD has significant socioeconomic implications. In a 20-year, longitudinal study of nearly 2400 patients with COPD, Garcia-Aymerich et $\mathrm{al}^{3}$ reported that physical activity levels equivalent to walking or cycling for at least $2 \mathrm{hrs} /$ week were associated with a $30 \%-40 \%$ reduction in the risk of COPD-related 
hospital admissions and mortality. In an earlier study, patients with COPD who were active at least 1 hour/ day had significantly lower risk of exacerbations and hospitalizations compared to patients with activity levels $\leq 20 \mathrm{~min} /$ day. ${ }^{51}$ These findings are important as COPD carries with it high social and economic costs. Specifically, in 2001, COPD in the United States was responsible for 16 million physician visits, 500,000 hospitalizations, 110,000 deaths, and 18 billion dollars in health care expenditures. ${ }^{52}$ Therefore, treatments that can effectively increase activity levels and improve long-term outcomes, can result in reductions in health care spending and in the overall burden of COPD.

\section{Study Limitations}

Although suggestions were provided to patients regarding suitable ADLs to perform, they were allowed to choose which activity was executed. Due to the wide variety of different activities selected, more direct comparisons between patients were not possible. However, given that the intent of the study was to evaluate a "real world" application of the NIOV system by allowing patients to perform a normal activity in the comfort of their own homes, this seemed to constitute a reasonable compromise. Data collected for this study occurred during a single at-home visit, which has obvious limitations for drawing conclusions about long-term outcomes. To address this, plans for a larger, long-term, randomized controlled trial to collect data on device utilization, pulmonary function status, and detailed health-related quality of life measures are currently under consideration.

\section{Conclusions}

We evaluated a new, portable noninvasive ventilator and nasal interface system to determine the effects on the performance of typical ADLs in oxygen-dependent patients in their home environment. NIOV use resulted in statistically and clinically meaningful improvements in ADL endurance, oxygenation, dyspnea, fatigue, and comfort, compared to standard oxygen therapy. Thus, the NIOV system appears to provide a practical option for increasing physical activity levels in patients who suffer from chronic respiratory insufficiency.

\section{Acknowledgments}

Author contributions: All authors had complete access to the data and reviewed and approved the manuscript. BWC served as principal investigator and takes responsibility for the integrity of the data and the accuracy of the data analysis. He contributed to the study concept and design and interpretation of the data. KSW and RWM contributed to data acquisition, the study concept and design and interpretation of the data. TB also contributed to data acquisition and interpretation of the data DE contributed to the study concept and design. RJM contributed to the study concept and design and interpretation of the data.

The sponsor, Breathe Technologies, assisted in the design of the study, the analysis of the data, and in the preparation of the manuscript including being involved in the draft of the manuscript and reviewing it in its final form regarding publication of proprietary information. No information was deleted.

The authors gratefully acknowledge the patients who volunteered to participate in this study and their families.

\section{Declaration of Interest}

RWM serves as a consultant to Breathe Technologies, Inc., which manufactures the NIOV system used in this study. RJM was an employee of Breathe Technologies, Inc. BWC, KSW, TB and DE report no potential conflicts of interest regarding companies or products discussed in this manuscript. 


\section{References}

1. Pitta F, Troosters T, Spruit MA, Probst VS, Decramer M, Gosselink R. Characteristics of physical activities in daily life in chronic obstructive pulmonary disease. Am J Respir Crit Care Med. 2005;171(9):972-977. doi: http://dx.doi.org/10.1164/rccm.200407-8550C

2. Garcia-Rio F, Rojo B, Casitas R, et al. Prognostic value of the objective measurement of daily physical activity in patients with COPD: physical activity and COPD prognostic measures. Chest. 2012;142(2):338-346. doi: http://dx.doi.org/10.1378/chest.11-2014

3. Garcia-Aymerich J, Lange P, Benet M, Schnohr P, Anto JM. Regular physical activity reduces hospital admission and mortality in chronic obstructive pulmonary disease: a population based cohort study. Thorax. 2006;61(9):772-778. doi: http://dx.doi.org/10.1136/thx.2006.060145

4. Goldstein RS, Hill K, Brooks D, Dolmage TE. Recent advances in pulmonary rehabilitation: a review of the recent literature. Chest. 2012;142(3):738-749.

doi: http://dx.doi.org/10.1378/chest.12-0188

5. Casaburi R, ZuWallack R. Pulmonary rehabilitation for management of chronic obstructive pulmonary disease. $N$ Engl J Med.2009;360(13):1329-1335. doi: http://dx.doi.org/10.1056/NEJMct0804632

6. Lacasse Y, Goldstein R, Lasserson TJ, Martin S. Pulmonary rehabilitation for chronic obstructive pulmonary disease. Cochrane Database Syst Rev. 2006(4):CD003793.

7. Ries AL, Bauldoff GS, Carlin BW, et al. Pulmonary Rehabilitation: Joint ACCP/AACVPR Evidence-Based Clinical Practice Guidelines. Chest. 2007;131(5 Suppl):4S-42S. doi: http://dx.doi.org/10.1378/chest.06-2418

8. Troosters T, Casaburi R, Gosselink R, Decramer M. Pulmonary rehabilitation in chronic obstructive pulmonary disease. Am J Respir Crit Care Med. 2005;172(1):19-38. doi: http://dx.doi.org/10.1164/rccm.200408-1109SO

9. Gimenez M, Servera E, Vergara P, Bach JR, Polu JM. Endurance training in patients with chronic obstructive pulmonary disease: a comparison of high versus moderate intensity. Arch Phys Med Rehabil. 2000;81(1):102-109.

10. Vallet G, Ahmaidi S, Serres I, et al. Comparison of two training programmes in chronic airway limitation patients: standardized versus individualized protocols. Eur Respir J. 1997;10(1):114-122. doi: http://dx.doi.org/10.1183/09031936.97.10010114

11. Emtner M, Porszasz J, Burns M, Somfay A, Casaburi R. Benefits of supplemental oxygen in exercise training in nonhypoxemic chronic obstructive pulmonary disease patients. Am J Respir Crit Care Med. 2003;168(9):1034-1042.

doi: http://dx.doi.org/10.1164/rccm.200212-1525OC

12. Garrod R, Paul EA, Wedzicha JA. Supplemental oxygen during pulmonary rehabilitation in patients with COPD with exercise hypoxaemia. Thorax. 2000;55(7):539-543. doi: http://dx.doi.org/10.1136/thorax.55.7.539

13. Chiappa GR, Queiroga F, Jr., Meda E, et al. Heliox improves oxygen delivery and utilization during dynamic exercise in patients with chronic obstructive pulmonary disease. Am J Respir Crit Care Med. June 1, 2009 2009;179(11):1004-1010.
14. Palange P. Lighter than air: heliox breathing improves exercise tolerance in COPD. Eur. Respir. Rev.

March 1, 2010 2010;19(115):1-3.

15. Vivodtzev I, Pépin J-L, Vottero G, et al. Improvement in quadriceps strength and dyspnea in daily tasks after 1 month of electrical stimulation in severely deconditioned and malnourished COPD. Chest. 2006;129(6):1540-1548. doi: http://dx.doi.org/10.1378/chest.129.6.1540

16. Beckerman M, Magadle R, Weiner M, Weiner P. The effects of 1 year of specific inspiratory muscle training in patients with COPD. Chest. 2005;128(5):3177-3182. doi: http://dx.doi.org/10.1378/chest.128.5.3177

17. Casaburi R, Kukafka D, Cooper CB, Witek TJ, Jr., Kesten S. Improvement in exercise tolerance with the combination of tiotropium and pulmonary rehabilitation in patients with COPD. Chest. 2005;127(3):809-817. doi: http://dx.doi.org/10.1378/chest.127.3.809

18. O’Donnell DE, Voduc N, Fitzpatrick M, Webb KA. Effect of salmeterol on the ventilatory response to exercise in chronic obstructive pulmonary disease. Eur Respir J. 2004;24(1):86-94. doi: http://dx.doi.org/10.1183/09031936.04.00072703

19. Casaburi R, Bhasin S, Cosentino L, et al. Effects of testosterone and resistance training in men with chronic obstructive pulmonary disease. Am J Respir Crit Care Med. 2004;170(8):870878. doi: http://dx.doi.org/10.1164/rccm.200305-617OC

20. Creutzberg EC, Wouters EF, Mostert R, Pluymers RJ, Schols AM. A role for anabolic steroids in the rehabilitation of patients with COPD? A double-blind, placebo-controlled, randomized trial. Chest. 2003;124(5):1733-1742. doi: http://dx.doi.org/10.1378/chest.124.5.1733

21. Slebos D-J, Klooster K, Ernst A, Herth FJF, Kerstjens HAM. Bronchoscopic lung volume reduction coil treatment of patients with severe heterogeneous emphysemalung volume reduction coil treatment of emphysema. Chest. 2012;142(3):574-582. doi: http://dx.doi.org/10.1378/chest.11-0730

22. Snell G, Herth FJF, Hopkins P, et al. Bronchoscopic thermal vapour ablation therapy in the management of heterogeneous emphysema. Eur Respir J. 2012;39(6):1326-1333. doi: http://dx.doi.org/10.1183/09031936.00092411

23. Ambrosino N, Carpenè N, Gherardi M. NIV and pulmonary rehabilitation. Noninvasive Ventilation. Vol 41: European Respiratory Society Journals Ltd; 2008:265-271. doi: http://dx.doi.org/10.1183/1025448x.00041018

24. Menadue C, Alison JA, Piper AJ, Flunt D, Ellis ER. Non-invasive ventilation during arm exercise and ground walking in patients with chronic hypercapnic respiratory failure. Respirology. 2009; 14(2):251-259. doi: http://dx.doi.org/10.1111/j.1440-1843.2008.01449.x

25. Costes F, Agresti A, Court-Fortune I, Roche F, Vergnon JM, Barthelemy JC. Noninvasive ventilation during exercise training improves exercise tolerance in patients with chronic obstructive pulmonary disease. J Cardiopulm Rehabil. 2003;23(4):307-313. doi: http://dx.doi.org/10.1097/00008483-200307000-00008

26. Dreher M, Storre JH, Windisch W. Noninvasive ventilation during walking in patients with severe COPD: a randomised cross-over trial. Eur Respir J. 2007;29(5):930-936. doi: http://dx.doi.org/10.1183/09031936.00075806 
27. Borghi-Silva A, Di Thommazo L, Pantoni CB, Mendes RG, Salvini Tde F, Costa D. Non-invasive ventilation improves peripheral oxygen saturation and reduces fatigability of quadriceps in patients with COPD. Respirology. 2009;14(4):537-544. doi: http://dx.doi.org/10.1111/j.1440-1843.2009.01515.x

28. Kohnlein T, Schonheit-Kenn U, Winterkamp S, Welte T, Kenn K. Noninvasive ventilation in pulmonary rehabilitation of COPD patients. Respir Med. 2009;103(9):1329-1336. doi: http://dx.doi.org/10.1016/j.rmed.2009.03.016

29. O’Donnell DE, Banzett RB, Carrieri-Kohlman V, et al. Pathophysiology of Dyspnea in Chronic Obstructive Pulmonary Disease: A Roundtable. Proc Am Thorac Soc. 2007;4(2):145-168. doi: http://dx.doi.org/10.1513/pats.200611-159CC

30. Pepin V, Saey D, Laviolette L, Maltais F. Exercise capacity in chronic obstructive pulmonary disease: Mechanisms of limitation. COPD. 2007;4(3):195-204. doi: http://dx.doi.org/10.1080/15412550701480489

31. Dunne PJ. The clinical impact of new long-term oxygen therapy technology. Respir Care. 2009;54(8):1100-1111.

32. Garrod R, Bestall JC, Paul E, Wedzicha JA. Evaluation of pulsed dose oxygen delivery during exercise in patients with severe chronic obstructive pulmonary disease. Thorax. 1999;54(3):242244. doi: http://dx.doi.org/10.1136/thx.54.3.242

33. Senn S, Wanger J, Fernandez E, Cherniack RM. Efficacy of a pulsed oxygen delivery device during exercise in patients with chronic respiratory disease. Chest.1989;96(3):467-472. doi: http://dx.doi.org/10.1378/chest.96.3.467

34. Lacasse Y, Lecours R, Pelletier C, Bégin R, Maltais F. Randomised trial of ambulatory oxygen in oxygen-dependent COPD. Eur Respir J. 2005;25(6):1032-1038. doi: http://dx.doi.org/10.1183/09031936.05.00113504

35. Nonoyama ML, Brooks D, Guyatt GH, Goldstein RS. Effect of oxygen on health quality of life in patients with chronic obstructive pulmonary disease with transient exertional hypoxemia. Am J Respir Crit Care Med. 2007;176(4):343-349. doi: http://dx.doi.org/10.1164/rccm.200702-3080C

36. Strickland SL, Hogan TM, Hogan RG, Sohal HS, McKenzie WN, Petroski GF. A randomized multi-arm repeated-measures prospective study of several modalities of portable oxygen delivery during assessment of functional exercise capacity. Respir Care. 2009;54(3):344-349.

37. Dreher M, Doncheva E, Schwoerer A, et al. Preserving oxygenation during walking in severe chronic obstructive pulmonary disease: noninvasive ventilation versus oxygen therapy. Respiration. 2009;78(2):154-160. doi: http://dx.doi.org/10.1159/000187717

38. McCabe L, Cayou C, Hilling L, Kops R, Heron G, Morishige R. Use of a novel non-invasive open ventilation system during rest, activities of daily living, and exercise in patients with severe COPD. Am J Respir Crit. Care Med. 2012;185:A5783.

39. Garvey C, Hilling L, Cayou C, Escobar R, Heron G, McCabe L. Open, noninvasive ventilation using a $1 \mathrm{lb}$ ventilator, oxygen, and a low profile mask improves 6MWT distances in advanced COPD. Am J Respir Crit Care Med. 2011;183:A3971

40. Hilling L, Cayou C, Wondka T, Kops R. Improved 6MWT distance with a highly portable non-invasive ventilator. Am J Respir Crit Care Med. 2010;181:A1198.
41. Wiles K, McCoy R, Brennan T, Carlin B. Augmented ventilation assistance to improve activities of daily living: a case study. Abstract presented at the American Association for Respiratory Care Congress 2012: Sunday, November 11, 2012, New Orleans, Louisiana.

42. Borg GA. Psychophysical bases of perceived exertion. Med Sci Sports Exerc. 1982;14(5):377-381. doi: http://dx.doi.org/10.1249/00005768-198205000-00012

43. Borghi-Silva A, Mendes RG, Toledo AC, et al. Adjuncts to physical training of patients with severe COPD: oxygen or noninvasive ventilation? Respir Care. 2010;55(7):885-894.

44. van 't Hul A, Gosselink R, Hollander P, Postmus P, Kwakkel G. Training with inspiratory pressure support in patients with severe COPD. Eur Respir J. 2006;27(1):65-72. doi: http://dx.doi.org/10.1183/09031936.06.00036505

45. Porszasz J, Cao R, Morishige R, van Eykern LA, Stenzler A, Casaburi R. Physiologic effects of an ambulatory ventilation system in chronic obstructive pulmonary disease. Am J Respir Crit Care Med. 2013;188(3):334-342. doi: http://dx.doi.org/10.1164/rccm.201210-17730C

46. Laude EA, Duffy NC, Baveystock C, et al. The effect of helium and oxygen on exercise performance in chronic obstructive pulmonary disease: a randomized crossover trial. Am J Respir Crit Care Med. 2006;173(8):865-870. doi: http://dx.doi.org/10.1164/rccm.200506-9250C

47. Palange P, Valli G, Onorati P, et al. Effect of heliox on lung dynamic hyperinflation, dyspnea, and exercise endurance capacity in COPD patients. J Appl Physiol. 2004;97(5):16371642. doi: http://dx.doi.org/10.1152/japplphysiol.01207.2003

48. Eves ND, Sandmeyer LC, Wong EY, et al. Helium-hyperoxia: a novel intervention to improve the benefits of pulmonary rehabilitation for patients with COPD. Chest. 2009;135(3):609618. doi: http://dx.doi.org/10.1378/chest.08-1517

49. Jolly EC, Di Boscio V, Aguirre L, Luna CM, Berensztein S, Gene RJ. Effects of supplemental oxygen during activity in patients with advanced COPD without severe resting hypoxemia. Chest. 2001;120(2):437-443.

doi: http://dx.doi.org/10.1378/chest.120.2.437

50. Fujimoto K, Matsuzawa Y, Yamaguchi S, Koizumi T, Kubo K. Benefits of oxygen on exercise performance and pulmonary hemodynamics in patients with COPD with mild hypoxemia. Chest. 2002;122(2):457-463. doi: http://dx.doi.org/10.1378/chest.122.2.457

51. Garcia-Aymerich J, Farrero E, Felez MA, et al. Risk factors of readmission to hospital for a COPD exacerbation: a prospective study. Thorax. 2003;58(2):100-105.

doi: http://dx.doi.org/10.1136/thorax.58.2.100

52. Yip NH, Yuen G, Lazar EJ, et al. Analysis of hospitalizations for COPD exacerbation: opportunities for improving care. COPD. 2010;7(2):85-92. doi: http://dx.doi.org/10.3109/15412551003631683 